\title{
Erratum to: Effects of Waterbird Colonization on Limnochemical Features of a Natural Wetland on Buxa Tiger Reserve, India, During Wintering Period
}

\author{
Asitava Chatterjee $^{1} \cdot$ Shuvadip Adhikari ${ }^{2} \cdot$ Subhra Kumar Mukhopadhyay $^{2}$
}

Published online: 2 January 2017

(C) Society of Wetland Scientists 2016

Erratum to: Wetland

DOI:10.1007/s13157-016-0851-7

Legends for figs. 3 and 4 were interchanged in the original article. The original article was corrected.

The online version of the original article can be found at http://dx.doi. org/10.1007/s13157-016-0851-7.

Shuvadip Adhikari

shuvaadhikari90@gmail.com

1 Office of the Divisional Manager, Alipurduar Forest Corporation Division, Alipurduar 736121, West Bengal, India

2 Ecotechnology Project Laboratory, Government College of Engineering and Leather Technology, Block- LB, Sector- III, Salt Lake, Kolkata 700 098, West Bengal, India 